\title{
THE ASSOCIATION BETWEEN GENE POLYMORPHISMS OF GLUTATHIONE $S$-TRANSFERASE T1/M1 AND TYPE 1 DIABETES IN SLOVAK CHILDREN AND ADOLESCENTS
}

\author{
Jarmila Vojtková1, Peter Ďurdík1, Miriam Čiljaková1, Zuzana Michnová1, Tomáš Turčan, Eva Babušíková2 \\ ${ }^{1}$ Department of Pediatrics, Comenius University in Bratislava, Jessenius Faculty of Medicine in Martin and University Hospital Martin, Martin, \\ Slovakia \\ 2Department of Medical Biochemistry, Comenius University in Bratislava, Jessenius Faculty of Medicine in Martin, Martin, Slovakia
}

\section{SUMMARY}

Background: Considering a dramatic increase in the incidence of type 1 diabetes (T1D) worldwide, current research focuses on complex etiology of T1D where immune system, environmental and genetic factors play a significant role. Glutathione $S$-transferase family of enzymes protects tissue from oxidative damage which is discussed in the context of T1D. The aim of the study was to investigate an association of glutathione S-transferase mu 1 (GST M1) and glutathione S-transferase theta 1 (GST T1) polymorphisms with type 1 diabetes.

Methods: 163 children, 116 with type 1 diabetes and 47 healthy controls, at the age 6-19 years were enrolled to the study. Basic anthropometric, biochemical parameters and GST T1 diabetes and M1 polymorphisms were established in each subject.

Results: Subjects with T1D had significantly lower concentration of uric acid compared to the healthy subjects $(212.85 \pm 57.10 \mu \mathrm{mol} / \mathrm{l}$ vs. $269.57 \pm 72.53 ; p<0.001)$. GST T1 null genotype was more frequent in patients with diabetes compared to the healthy controls $(36.2 \%$ vs. $21.3 \%)$ and represented 2.1-fold increased risk of T1D of borderline statistical significance (OR=2.1; 95\% Cl=0.949-4.648; $p=0.06)$. GST T1 null/M1 wild genotype combination was more frequent in patients with diabetes (25.9\% vs. 10.6\%) and represented 2.9-fold increased risk for T1D development (OR=2.93; 95\% $\mathrm{Cl}=1.061-8.095 ; \mathrm{p}=0.032$ ).

Conclusion: The study indicates that GST T1 null genotype and GST T1 null/M1 wild combination could be considered a risk factor for type 1 diabetes development in Slovak children and adolescents.

Key words: type 1 diabetes, glutathione S-transferase T1 and M1, gene polymorphisms

Address for correspondence: J. Vojtková, University Hospital Martin, Kollárova 2, 03601 Martin, Slovakia. E-mail: jarmilavojtkova@gmail.com

\section{INTRODUCTION}

Epidemiological studies indicate that the incidence and prevalence of type 1 diabetes mellitus (T1D) is rising worldwide. The incidence rate of childhood T1D across Europe rises nonuniformly every year by an average of 3-4\% (1). In Slovakia, a 2.57-fold increase in the incidence of T1D from 1986 to 1998 was the highest among children 10-14 years of age and increased dramatically especially in children $0-4$ years old (2). Although significant effort has been made to improve the quality of life and clinical outcomes in patients with T1D, much more needs to be done to find the prevention and cure of T1D. Therefore, research of risk factors of T1D is necessary to identify triggers that could potentially be targeted for intervention. Current studies focus on predisposing factors in complex etiology of T1D, where immune system, environmental triggers and genetic susceptibility play a significant role. One of the pathways discussed in the etiopathogenesis of T1D is oxidative stress (3) characterized as an imbalance between reactive oxygen species (ROS) production and antioxidant mechanisms. ROS are liberated by activated macrophages and $\mathrm{T}$ lymphocytes and are induced by proinflammatory cytokines involved in autoimmune process of pancreatic beta cells. An increased level of ROS causes oxidative modification of proteins and nucleic acids and lipid peroxidation. These changes may result in alteration in biological functions of all biomolecules, in metabolism of all tissues and cell damage including beta cells.

Glutathione $S$-transferase (GST) represents a family of enzymes catalyzing the conjugation of glutathione with various electrophilic compounds to facilitate their excretion (4). The broad substrate specificity of GSTs allows them to protect cells against a range of toxic chemicals, however, this GST activity can be deleterious in certain cases, as it can cause chemotherapy resistance or the arisen metabolite can be more toxic than the primary molecule (5). GST enzymes are involved in the synthesis of inflammatory mediators, leukotrienes and prostaglandins and act also in cell signaling pathway as potential regulators of apoptosis. Regarding their function within oxidative stress, GSTs detoxify some of the secondary ROS generated during oxidation of membranes or other cellular constituents. GSTs act in the detoxification of organic hydroperoxides and protect cells from peroxide-induced cell death (6). 
According to substrate specificity, chemical affinity, structure, sequence, and kinetic behaviour, few classes of soluble GSTs have been identified (alpha, kappa, mu, pi, theta, zeta, omega, and sigma). The most researched one is glutathione $S$-transferase mu 1 (GST M1) enzyme in GST M class with its gene located in Chromosome 1p13.3 and glutathione $S$-transferase theta 1 (GST T1) enzyme in GST T class with its gene located in Chromosome 22q11.23. It has been shown that individuals carrying the null genotype of GST have significantly reduced activity of this enzyme compared to wild genotype carriers (7).

According to recent studies, GST T1 and M1 are regarded as candidate polymorphisms for susceptibility to type 2 diabetes (T2D) (8) or chronic diabetic complications (9). The majority of studies have focused on adult subjects with T2D, only one collective of authors has targeted young subjects with T1D (10). The aim of this study was to determine the association between T1D and GST T1 and M1 gene polymorphisms in Slovak children and adolescents.

\section{MATERIALS AND METHODS}

\section{Study Subjects and Studied Parameters}

The study was approved by the Ethical Committee of Jessenius Faculty of Medicine in Martin, Slovakia, in accordance with the ethical standards. 163 enrolled subjects, at the age 6-19 years, and their legal representatives were informed about the aim of the study and signed informed consent. The study group was represented by 116 patients with T1D (53 females, 63 males, average age $12.95 \pm 4.13$ years, average diabetes duration $5.00 \pm 3.97$ years), diagnosis based on criteria of the American Diabetes Association (11). The control group was represented by 47 healthy volunteers ( 25 females, 22 males, average age $13.98 \pm 3.32$ years) with matched age and sex in which diabetes mellitus, obesity, cardiovascular, respiratory, and nervous diseases were excluded.

Information about duration and onset of diabetes in subjects with T1D and basic anthropometric parameters - height, weight and body mass index (BMI) in each subject were obtained. Basic biochemical parameters - glucose, glycosylated hemoglobin, cholesterol, triacylglycerol, bilirubin, uric acid, and creatinine were established from blood sample in each child.

\section{DNA Extraction and Polymorphism Detection}

Genomic DNA was extracted from peripheral venous blood using standard phenol - chloroform method. GST T1 and M1 genetic polymorphisms were evaluated using the multiplex polymerase chain reaction (PCR) technique. Primers for GST M1 polymorphisms were 5'-GAACTCCCTGAAAAGCTAAAGC-3' and 5'-GTTGGGCTCAAATATACGGTGG-3' and for GST T1 5'-TTCGTTACTGGTCCTCACATCTC-3' and 5'-TCACGGGATCATGGCCAGCA-3'. The beta-globin was used as a locus control to avoid false-negative readings. Primers for beta-globin were 5'-CAACTTCATCCACGTTCACC-3' and 5'-GAAGAGCCAAGGACAGGTAC-3'. The PCR products were electrophoresed in agarose gel and visualized by ethidium bromide staining. The length of products was $215 \mathrm{bp}, 480 \mathrm{bp}$ and 268 bp for GST M1, GST T1 and beta-globin, respectively.

\section{Statistical Analysis}

The results were processed by statistic program SYSTAT (version 11). The observed parameters were expressed as mean \pm standard error (SE). Students' t-test was used to assess significant difference between subgroups and $\mathrm{p}<0.05$ was considered statistically significant. Genotype frequencies were compared using chi-square $\left(\chi^{2}\right)$ test. Odds ratio (OR) with $95 \%$ confidence interval $(95 \% \mathrm{CI})$ calculated by logistic regression was used to describe the strength of association.

\section{RESULTS}

\section{Characteristics of Diabetic and Control Subjects}

Subjects with T1D had significantly lower concentration of uric acid $(212.85 \pm 57.10 \mu \mathrm{mol} / 1$ vs. $269.57 \pm 72.53 ; \mathrm{p}<0.001)$ and creatinine $(74.42 \pm 17.05 \mathrm{mmol} / \mathrm{l}$ vs. $79.89 \pm 13.30$; $\mathrm{p}=0.026)$ compared to the healthy subjects. Higher concentration of cholesterol in children with T1D was of borderline statistical significance $(4.45 \pm 1.01 \mathrm{mmol} / 1$ vs. $4.17 \pm 0.55 ; \mathrm{p}=0.059)$. No significant difference was found in BMI, concentration of bilirubin and triacylglycerol (Table 1).

\section{GST T1 and M1 Gene Polymorphisms in Diabetic and Control Subjects}

The frequency of GST T1 null genotype was $36.2 \%$ in the diabetic group and $21.3 \%$ in the control group. It represented 2.1 -fold increased risk of T1D, however, this finding was of borderline statistical significance $(\mathrm{OR}=2.1 ; 95 \% \mathrm{CI}=0.949-4.648 ; \mathrm{p}=0.064)$. No significant difference was found in GST M1 genotypes between diabetic and healthy subjects (Table 2), the frequency of GST M1 null genotype was $39.7 \%$ and $40.4 \%$, respectively.

Double analysis of GST genotypes revealed that T1D patients had significantly more frequent occurrence of GST T1 null/ M1 wild genotype compared to the healthy controls (25.9\% vs. $10.6 \%$, respectively) and this combination of alleles 2.9 -times increased the risk of $11 \mathrm{D}\left(\mathrm{OR}=2.93 ; 95 \% \mathrm{CI}=1.061-8.095 ; \chi^{2}=4.6\right.$; $\mathrm{p}=0.032)$. GST T1 null/M1 null genotype as well as other genotype combinations did not show the significant difference (Table 3 ).

\section{DISCUSSION}

GST T1 and M1 polymorphisms were supposed to have an influence on pathogenesis of numerous conditions like allergy, bronchial asthma, coronary artery disease, cancer, or hypertension (12-16). As GSTs are involved in the detoxification of secondary ROS and in synthesis of proinflammatory mediators, both contributing to pancreatic beta cell damage, we hypothesize that GST polymorphisms may play role in the etiology of T1D.

We observed that GST T1 null genotype was more frequent in subjects with T1D compared to the healthy children, and represented 2.1-fold increased risk of T1D of borderline statistical significance. Genotype combination GST T1 null/M1 wild was significantly more prevalent in subjects with diabetes and represented 2.9-fold risk for T1D developing. The majority of studies on GST T1/M1 gene polymorphisms have reported that 
Table 1. Clinical characteristics of diabetic and control group

\begin{tabular}{|c|c|c|c|}
\hline & $\begin{array}{c}\text { Diabetic group }(\mathrm{N}=116) \\
\text { mean } \pm \mathrm{SE}\end{array}$ & $\begin{array}{c}\text { Control group ( } \mathrm{N}=46) \\
\text { mean } \pm \mathrm{SE}\end{array}$ & $\mathrm{p}$ \\
\hline Age (years) & $12.95 \pm 4.13$ & $13.98 \pm 3.32$ & 0.092 \\
\hline Duration of diabetes (years) & $5.00 \pm 3.97$ & - & - \\
\hline Onset of diabetes (years) & $7.82 \pm 4.29$ & - & - \\
\hline $\mathrm{BMI}\left(\mathrm{kg} / \mathrm{m}^{2}\right)$ & $18.99 \pm 3.46$ & $19.96 \pm 3.33$ & 0.087 \\
\hline Fasting glucose (mmol/l) & $11.70 \pm 4.46$ & $4.94 \pm 0.44$ & $<0.001$ \\
\hline Glycosylated hemoglobin (\%) & $10.24 \pm 1.95$ & $6.22 \pm 0.68$ & $<0.001$ \\
\hline Cholesterol (mmol/l) & $4.45 \pm 1.01$ & $4.17 \pm 0.55$ & 0.059 \\
\hline Triacylglycerol (mmol/l) & $1.14 \pm 0.73$ & $0.98 \pm 0.43$ & 0.107 \\
\hline Creatinine $(\mathrm{mmol} / \mathrm{l})$ & $74.42 \pm 17.05$ & $79.89 \pm 13.30$ & 0.026 \\
\hline Uric acid $(\mu \mathrm{mol} / \mathrm{l})$ & $212.85 \pm 57.10$ & $269.57 \pm 72.53$ & $<0.001$ \\
\hline Bilirubin (mmol/l) & $13.18 \pm 6.02$ & $12.87 \pm 5.46$ & 0.383 \\
\hline
\end{tabular}

SE - standard error; $p$ - statistic probability

Table 2. Glutathione S-transferase T1 (GST-T1) and M1 (GST-M1) genotype and the risk of developing type 1 diabetes mellitus (T1D)

\begin{tabular}{|l|c|c|c|c|c|c|}
\hline & $\begin{array}{c}\text { Control group } \\
(\mathrm{N}=47) \\
\mathrm{n}(\%)\end{array}$ & $\begin{array}{c}\text { T1D } \\
(\mathrm{N}=116) \\
\mathrm{n}(\%)\end{array}$ & OR & 95\% Cl & Chi-square \\
\hline GST-T1 & $37(78.7)$ & $74(63.8)$ & - & - & - & - \\
\hline wild & $10(21.3)$ & $42(36.2)$ & 2.1 & $0.949-4.648$ & 3.43 & 0.064 \\
\hline null & $28(59.6)$ & $70(60.3)$ & - & - & \multicolumn{2}{|c|}{-} \\
\hline GST-M1 & $19(40.4)$ & $46(39.7)$ & 0.968 & $0.485-1.933$ & 0.01 & 0.920 \\
\hline wild &
\end{tabular}

$\mathrm{n}$ - number of subjects; $\mathrm{p}$ - statistic probability; $\mathrm{OR}$ - odds ratio; $\mathrm{Cl}$ - confidence interval

Table 3. Double analysis of glutathione S-transferase genotypes and the risk of developing type 1 diabetes mellitus (T1D)

\begin{tabular}{|c|c|c|c|c|c|c|c|}
\hline GST-T1 & GST-M1 & $\begin{array}{c}\text { Control group } \\
(\mathrm{N}=47) \\
\mathrm{n}(\%)\end{array}$ & $\begin{array}{c}\text { T1D } \\
(\mathbf{N}=116) \\
\mathrm{n}(\%)\end{array}$ & OR & 95\% Cl & Chi-square & $\mathbf{p}$ \\
\hline wild & wild & $23(49)$ & $40(34.5)$ & 0.549 & $0.276-1.093$ & 2.95 & 0.086 \\
\hline wild & null & $14(29.8)$ & $34(29.3)$ & 0.977 & $0.465-2.053$ & 0 & 1 \\
\hline null & wild & $5(10.6)$ & $30(25.9)$ & 2.93 & $1.061-8.095$ & 4.6 & 0.032 \\
\hline null & null & $5(10.6)$ & $12(10.3)$ & 0.969 & $0.322-2.921$ & - & - \\
\hline
\end{tabular}

$\mathrm{n}$ - number of subjects; $\mathrm{p}$ - statistic probability; OR - odds ratio; $\mathrm{Cl}$ - confidence interval

null genotypes represented an increased risk of the disease $(8,9$, 13-15). It may be explained by the fact that carriers of GST null genotype have significantly lower activity of this antioxidant enzyme (7). Only one collective of authors has reported that null genotype is associated with disease protection (10), it may be explained by several speculative possibilities. First, the absence of GST may upregulate other antioxidant genes like superoxide dismutase (17). Second, GST enzymes are normally involved in the synthesis of inflammatory mediators, leukotrienes and prostaglandins (4), so lack of GST activity may lead to decrease in the inflammatory response and to protection against T1D. Third, an unknown compound may be metabolized by GST into a toxic form, so null genotype would be protective, such as dihaloalkanes are bioactivated by increased activity of GST T1 into more genotoxic metabolites (5) or GST pi knockout mice are protected against acetaminophen toxicity as acetaminophen is not activated into its toxic metabolite (18).

To the best of our knowledge, only one study deals with GST polymorphisms and diabetes susceptibility in patients with T1D, till now. In the young Swedish population, no association was found regarding GST T1 genotype. GST M1 wild genotype was associated with a higher risk of T1D in the group of 14-20 years old subjects and GST M1 null genotype was regarded as protective (10). Similarly to Bekris et al., we claim that GST M1 wild increases the risk of T1D, however, in our study not itself but in combination with GST T1 null allele. This discrepancy may be 
caused by different geographical area and studied population. Probably, insufficient antioxidant activity due to GST T1 null allele together with one of the speculative possibilities due to GST M1 wild allele represent the risk factor for Slovak subjects with T1D. We acknowledge that the number of our subjects, especially in the control group, is not extensive, however, these results could be useful considering the few studies dealing with the same topic. Moreover, the presence of polymorphisms is comparable with other published works. The prevalence of GST $\mathrm{T} 1$ null genotype was $21.3 \%$ in our control group and $20.4 \%$ in the Caucasian population (19). GST M1 null genotype was present with a frequency of $40.4 \%$ in our control subjects, compared to $38-62 \%$ in European countries (20).

In our study, subjects with diabetes had significantly lower concentration of uric acid compared to the controls. As uric acid is considered to be an antioxidant, this result can indicate lower antioxidant status or increased consumption of uric acid due to oxidative stress in subjects with diabetes. Uric acid is also considered to be a marker of metabolic syndrome (21), however, in our study other markers of metabolic syndrome (cholesterol, triacylglycerol and BMI) did not show the same tendency. Finally, the uric acid is one of the nitrogen compounds excreted by kidneys. Its lower concentration could be explained by hyperfiltration of kidneys as the early diabetic complication which is enhanced by the finding of the same creatinine concentration trend.

To sum up, imbalance between ROS production and antioxidant mechanisms as well as gene polymorphisms of GSTs, enzymes with various functions may contribute to T1D development. Our results suggest that gene polymorphisms of antioxidant enzyme glutathione $S$-transferase may play a partial role in pathogenesis of type 1 diabetes. GST T1 null genotype and combination GST T1 null/M1 wild can be regarded as the risk factors for T1D development in children and adolescents in the Slovak population. Further investigations with extended number of subjects are needed to clarify these associations.

\section{Acknowledgements}

The work was supported by grant "OPV 26110230031/04/D/2010" and by the project "Center of Experimental and Clinical Respirology (CEKR II)" co-financed by the EU.

\section{Conflict of Interest}

None declared

\section{REFERENCES}

1. Patterson CC, Gyürüs E, Rosenbauer J, Cinek O, Neu A, Schober E, et al. Trends in childhood type 1 diabetes incidence in Europe during 1989-2008: evidence of non-uniformity over time in rates of increase. Diabetologia. 2012 Aug;55(8):2142-7.

2. Michalková D, Minárik P, Hlava P, Čamajová J, Nazarov V; Slovak Epidemiological Study Group of Children Diabetologists. Trends in the incidence of childhood-onset type 1 diabetes in Slovakia 1985 - 2000. Cent Eur J Public Health. 2004 Jun;12(2):75-7.

3. Delmastro MM, Piganelli JD. Oxidative stress and redox modulation potential in type 1 diabetes. Clin Dev Immunol. 2011;2011:593863.

4. Hayes JD, Flanagan JU, Jowsey IR. Glutathione transferases. Annu Rev Pharmacol Toxicol. 2005;45:51-88.

5. Sherratt PJ, Manson MM, Thomson AM, Hissink EA, Neal GE, van Bladeren PJ, et al. Increased bioactivation of dihaloalkanes in rat liver due to induction of class theta glutathione S-transferase T1-1. Biochem J. 1998 Nov 1;335(Pt 3):619-30.

6. Veal EA, Toone WM, Jones N, Morgan BA. Distinct roles for glutathione S-transferases in the oxidative stress response in schizosaccharomyces pombe. J Biol Chem. 2002 Sep 20;277(38):35523-31.

7. Datta SK, Kumar V, Ahmed RS, Tripathi AK, Kalra OP, Banerjee BD. Effect of GSTM1 and GSTT1 double deletions in the development of oxidative stress in diabetic nephropathy patients. Indian J Biochem Biophys. 2010 Apr;47(2):100-3.

8. Hori M, Oniki K, Ueda K, Goto S, Mihara S, Marubayashi T, et al. Combined glutathione-S-transpherase T1 and M1 positive genotype afford protection against type 2 diabetes in Japanese. Pharmacogenomics. 2007 Oct;8(10):1307-14

9. Ramprasath T, Senthil Murugan P, Prabakaran AD, Gomathi P, Rathinavel A, Selvam GS. Potential risk modifications of GSTT1, GSTM1 and GSTP1 (glutathione-S-transferases) variants and their association to CAD in patients with type-2 diabetes. Biochem Biophys Res Commun. 2011 Apr 1;407(1):49-53

10. Bekris LM, Shephard C, Peterson M, Hoehna J, Van Yserloo B, Rutledge E, et al. Glutathione-s-transpherase M1 and T1 polymorphisms and associations with type 1 diabetes age-at-onset. Autoimmunity. 2005 Dec;38(8):567-75.

11. American diabetes association. Diagnosis and classification of diabetes mellitus. Diabetes Care. 2012 Jan;35 Suppl 1:S64-71.

12. Jesenak M, Banovcin P, Rennerova Z, Jakusova L, Havlicekova Z, Pohanka $\mathrm{V}$, et al. Reproducibility of food atopy patch tests over time in the general child population. Int J Dermatol. 2009 Sep;48 (9):941-6.

13. Babusikova E, Jesenak M, Kirschnerova R, Banovcin P, Dobrota D. Association of oxidative stress and GST-T1 gene with childhood bronchial asthma. J Physiol Pharmacol. 2009 Nov;60 Suppl 5:S27-30.

14. Manfredi S, Calvi D, del Fiandra M, Botto N, Biagini A, Andreassi MG. Glutathione S-transferase T1- and M1- null genotypes and coronary artery disease risk in patients with Type 2 diabetes mellitus. Pharmacogenomics. 2009 Jan;10(1):29-34

15. Economopoulos KP, Sergentanis TN. GSTM1, GSTT1, GSTP1, GSTA1 and colorectal cancer risk: a comprehensive meta-analysis. Eur J Cancer. 2010 Jun;46(9):1617-31.

16. Borah PK, Shankarishan P, Mahanta J. Glutathione S-transferase M1 and $\mathrm{T} 1$ gene polymorphisms and risk of hypertension in tea garden workers of North-East India. Genet Test Mol Biomarkers. 2011 Nov;15(11):771-6.

17. Otto-Knapp R, Jurgovsky K, Schierhorn K, Kunkel G. Antioxidative enzymes in human nasal mucosa after exposure to ozone. Possible role of GSTM1 deficiency. Inflamm Res. 2003 Feb;52(2):51-5.

18. Henderson CJ, Wolf CR, Kitteringham N, Powell H, Otto D, Park BK. Increased resistance to acetaminophen hepatotoxicity in mice lacking glutathione S-transferase Pi. Proc Natl Acad Sci U S A. 2000 Nov 7;97(23):12741-5

19. Nelson HH, Wiencke JK, Christiani DC, Cheng TJ, Zuo ZF, Schwartz $\mathrm{BS}$, et al. Ethnic differences in the prevalence of the homozygous deleted genotype of glutathione S-transferase theta. Carcinogenesis. 1995 May; 16(5):1243-5.

20. Lin HJ, Han CY, Bernstein DA, Hsiao W, Lin BK, Hardy S. Ethnic distribution of the glutathione transferase Mu 1-1 (GSTM1) null genotype in 1473 individuals and application to bladder cancer susceptibility. Carcinogenesis. 1994 May;15(5):1077-81.

21. Meisinger C, Döring A, Stöckl D, Thorand B, Kowall B, Rathmann W. Uric acid is more strongly associated with impaired glucose regulation in women than in men from the general population: the KORA F4-Study. PLoS One. 2012 May 16;7(5):e37180.

Received June 27, 2012

Accepted in revised form January 24, 2013 